\title{
Glutamate and cyclic AMP regulate the expression of galactokinase in Mycobacterium smegmatis
}

\author{
Santanu Raychaudhuri, Madhumita Basu and Nitai C. Mandal \\ Author for correspondence: Nitai C. Mandal. Tel: +9133 337 9544. Fax: +91333343886. \\ e-mail:ncmandal@boseinst.ernet.in
}

Department of Biochemistry, Bose Institute, Acharya J.C. Bose Birth Centenary Building, P-1/12, CIT Scheme VII M, Calcutta 700054, India

\begin{abstract}
It was found that Mycobacterium smegmatis is unable to utilize galactose as the sole carbon source because the sugar alone cannot induce galactokinase. However, galactokinase was induced by glutamate alone, and was further stimulated by galactose. Rifampicin completely inhibited the glutamatemediated expression of ga/K in both the absence and presence of galactose. Extracellular CAMP stimulated the expression of the enzyme only in the presence of glutamate plus galactose. The galK gene from $M$. smegmatis, including its upstream promoter region, was cloned in a plasmid in Escherichia coli. The expression of kinase from these clones in $E$. coli was dependent on CAMP and its receptor protein (CRP). The expression of UDP-galactose 4epimerase was constitutive. This and other evidence suggests that the galK gene is not linked to galT and galE in the mycobacterial genome. In a glutamate-independent galactose-utilizing mutant (gin-1 mutant) of $\boldsymbol{M}$. smegmatis, galK was expressed in the absence of both galactose and glutamate, while in the presence of galactose this expression was increased twofold in the absence of glutamate and fourfold in its presence.

Extracellularly added cAMP reduced the expression of the enzyme in the presence of galactose plus glutamate nearly to the basal level. It is proposed that in $M$. smegmatis the galK gene is expressed from two different promoters; the expression from one promoter is dependent on glutamate but not on galactose and CAMP, while that from the other requires all three components. The role of galactose is possibly to derepress the latter promoter.
\end{abstract}

Keywords: Mycobacterium smegmatis, gene regulation, galactokinase induction, glutamate, galK operon

\section{INTRODUCTION}

Although mycobacteria are among the earliest identified human pathogens, their genetics and gene regulation are poorly understood (Dale \& Patki, 1990; Grange, 1983; Greenberg \& Woodley, 1985; Jacobs, 1992). The main reasons for this lack of information are the slow growth rate of the organism, poorly developed gene transfer systems and very little understanding of the genetic background of these bacteria. However, efforts are now being made to explore the mechanisms of gene regulation in mycobacteria. It has been shown that mycobacterial promoters function poorly in Escherichia coli (Bashyam et al., 1996; Clark-Curtiss et al., 1985; Das Gupta et al., 1993; Kieser et al., 1986). Although a

Abbreviation: CRP, CAMP receptor protein. number of mycobacterial metabolic genes have been cloned by complementation of the mutational defects in the corresponding genes of $E$. coli (Anderson et al., 1993; Garbe et al., 1990; Jacobs et al., 1986; Stelandre et al., 1992) and mycobacteria (Hinshelwood \& Stoker, 1992), very little is known about the regulatory mechanisms involved. More studies are needed to understand the basic features of the regulation of mycobacterial gene expression.

Galactose is a major component of the mycobacterial cell wall, where it exists as arabinogalactan mycolate covalently linked to peptidoglycan (Kasuka et al., 1981; Minnikin et al., 1985; Segal \& Edwards, 1985). DGalactose induces $\mathrm{L}$-arabinose permease and L-arabinose isomerase in Mycobacterium smegmatis. Whereas the former enzyme is capable of transporting galactose into the bacterial cell, the latter cannot use this sugar as 
a metabolic substrate (Izumori et al., 1976, 1978). We observed that $M$. smegmatis could not use galactose as the sole carbon source unless glutamate was also present in the medium. Although glutamate has routinely been used as a component of mycobacterial growth media (Lyon et al., 1967), nothing is known about its involvement in gene regulation in these bacteria. In no other micro-organism is glutamate known to regulate the catabolic utilization of any sugar. Given this situation, we were interested to study the expression of gal genes in M. smegmatis in the hope of shedding new light on the mechanism of gene regulation in this bacterium at the molecular level. In this paper we show that in $M$. smegmatis galactose alone cannot induce galactokinase, while glutamate alone can do so to a certain level, which is increased further when galactose is also present in the growth medium. The expression of UDP-galactose 4-epimerase is constitutive. Results of the experiments described here suggest that in this mycobacterium, galactokinase is expressed from two different promoters.

\section{METHODS}

Materials. Bacterial strains and plasmids are described in Table 1 . The restriction and other enzymes and $\left[{ }^{14} \mathrm{C}\right]$ galactose were purchased from Amersham. All other chemicals were obtained from Sigma.
Media and solutions. Middlebrook 7H9 broth ('7H9 broth'), a supplemented minimal salt medium, and $7 \mathrm{H} 9$ hard agar have been described by Chaudhuri et al. (1993). The basal 7H9 broth was prepared by omitting carbon sources such as citrate, glutamate and sugar from $7 \mathrm{H} 9$ broth. The basal hard agar contained $1.5 \%(\mathrm{w} / \mathrm{v})$ agar in basal $7 \mathrm{H} 9$ broth. The M9 medium was as described by Miller (1972). Unless otherwise mentioned, the percentage concentrations of galactose and glutamate are defined as $w / v$ and of glycerol as $v / v$.

Growth of bacteria. Mycobacterial cultures were routinely grown with shaking at $37^{\circ} \mathrm{C}$ in the desired medium containing $0.05 \%(\mathrm{v} / \mathrm{v})$ Tween 80 . Growth was monitored by measuring $\mathrm{OD}_{590}$ in a spectrophotometer (Beckman DU-6). For the transport and enzyme assays, cells were processed at $0-4{ }^{\circ} \mathrm{C}$.

Galactose uptake. M. smegmatis was grown to around $\mathrm{OD}_{590}$ 1 in basal 7H9 broth with or without supplementation(s). The cells were then processed and the galactose uptake activity was assayed as described by Prasad et al. (1976) except that ${ }^{14} \mathrm{C}$ labelled amino acid was replaced by $\left[{ }^{14} \mathrm{C}\right]$ galactose $\left(10^{5}\right.$ c.p.m. $\mathrm{ml}^{-1}$; 50 c.p.m. nmol ${ }^{-1}$ ) and aliquots of the cells containing transported radioactivity were washed with $10 \mathrm{ml}$ chilled solution of $0.2 \%$ nonradioactive galactose on a Millipore filter.

Galactokinase and UDP-galactose 4-epimerase assays. The bacteria were grown under the desired conditions and the cells were harvested, washed with M9 salt $(1 \times)$ solution and suspended in the same solution. This cell suspension was divided into two equal portions. To one portion was added

Table 1. Strains and plasmids

\begin{tabular}{|c|c|c|}
\hline Strain/plasmid & $\begin{array}{l}\text { Alternative } \\
\text { designation }\end{array}$ & Source* \\
\hline \multicolumn{3}{|l|}{ M. smegmatis } \\
\hline $\mathrm{mc}^{2} 6$ (wild-type) & $\mathrm{mc}^{2} 6$ & Snapper et al. (1988) \\
\hline $\mathrm{mc}^{2} 6$ gin -1 & $\operatorname{gin}-1$ & This study \\
\hline \multicolumn{3}{|l|}{ E. coli } \\
\hline $\begin{array}{l}\text { DH5 (supE44 bsdR17 recA1 endA1 } \\
\text { gyrA96 thi-1 relA1) }\end{array}$ & DH5 & Sambrook et al. (1989) \\
\hline SA1527 (galE Str ${ }^{\mathrm{r}}$ his relA) & gale & S. Adhya \\
\hline SA2285 (galT Str his relA1) & galT & S. Adhya \\
\hline $\begin{array}{l}\text { DJ189 (thr leu supE thi } \mathrm{r}^{-} \mathrm{m}^{-} \text {lac } \mathrm{Str}^{\mathrm{r}} \\
\text { recA galK srl::Tn10) }\end{array}$ & galK & D. Chattoraj \\
\hline $\begin{array}{l}\text { MC4100 }[\text { araD139 } \Delta(\text { lac }) U 169 \\
\text { rpsL thi] }\end{array}$ & $\mathrm{galK}^{+}$ & H. Aiba \\
\hline IT1375 [MC4100 $\Delta(c y a::$ kan $)]$ & $\Delta($ cya $) \mathrm{galK}^{+}$ & H. Aiba \\
\hline IT1376 [MC4100 $\Delta($ crp::kan] & $\Delta(\operatorname{crp}) \mathrm{galK}^{+}$ & H. Aiba \\
\hline \multicolumn{3}{|l|}{ Plasmids } \\
\hline pBend2 & & Zweib et al. (1989) \\
\hline pTAC3734 & & T. Atlung \\
\hline pGK1 & & This study \\
\hline pGK2 & & This study \\
\hline pGK4 & & This study \\
\hline pGK6 & & This study \\
\hline pGKgin-1 & & This study \\
\hline
\end{tabular}

*S. Adhya and D. Chattoraj, Laboratory of Molecular Biology, NCI, NIH, Bethesda, MD, USA; H. Aiba, Laboratory of Molecular Microbiology, School of Agriculture, Nagoya University, Japan; T. Atlung, Department of Microbiology, Technical University of Denmark. 
DTT to $1 \mathrm{mM}$ and EDTA to $2 \mathrm{mM}$, and the cells were sonicated in a Braunsonic model 1510 sonicator. This total extract was used to assay galactokinase (EC 2.7.1.6) by the method of Adhya \& Miller (1979) using $\left[{ }^{14} \mathrm{C}\right]$ galactose as substrate. One unit of kinase activity was defined as the amount of enzyme which could produce $1 \mathrm{nmol}$ galactose 1 phosphate $\min ^{-1}$ under the conditions of the assay. Cells from the second portion were washed with $50 \mathrm{mM}$ potassium phosphate buffer, $\mathrm{pH} 7 \cdot 8$, suspended in the same buffer and sonicated. This extract was used to assay UDP-galactose 4epimerase (EC 5.1.3.2) as described by Wilson $\&$ Hogness (1969). One unit of epimerase activity was defined as the amount of enzyme that produced a change of $1 \mathrm{OD}_{340}$ unit per min due to $\mathrm{NADH}^{+}$formed in a coupled reaction involving UDP-galactose, UDP-glucose dehydrogenase and $\mathrm{NAD}^{+}$in the presence of the extract.

Isolation of glutamate-independent galactose-utilizing mutants of $\boldsymbol{M}$. smegmatis. The bacteria were grown in $7 \mathrm{H} 9$ broth containing $0 \cdot 2 \%$ glycerol to around $\mathrm{OD}_{590} 1$ and treated with $N^{\prime}$-methyl- $N^{\prime}$-nitro- $N$-nitrosoguanidine to $0 \cdot 001-0.01 \%$ survival by the method described by Miller (1972). These cells were washed, grown in $7 \mathrm{H} 9$ broth for $24 \mathrm{~h}$ and then starved in basal $7 \mathrm{H} 9$ for $24 \mathrm{~h}$. The starved cells were plated on basal $7 \mathrm{H} 9$ agar containing $0.2 \%$ galactose. After $4-5 \mathrm{~d}$ at $37^{\circ} \mathrm{C}$, the healthy colonies were taken as the putative glutamateindependent galactose-utilizing (gin) mutants of $\mathrm{mc}^{2} 6$ and were purified.

Preparation of the genomic libraries of wild-type $\boldsymbol{M}$. smegmatis and its gin-1 mutant in E. coli. The genomic DNA from mycobacterial cells was isolated by the procedure described by Chaudhuri et al. (1993). This DNA was digested partially with Sau3AI, and $1-4 \mathrm{~kb}$ fragments were gel-purified and ligated to a BamHI-digested plasmid having no promoter at its multiple cloning sites. The ligated DNA mixture was then transformed in $E$. coli $\mathrm{DH} 5$ by the $\mathrm{CaCl}_{2}$ method (Sambrook et al., 1989). The transformant colonies grown on ampicillin agar were pooled from several plates and plasmid DNAs were isolated. This gave the Sau3AI genomic library of M. smegmatis in an E. coli plasmid.

Northern analysis. Total RNA from $\mathrm{mc}^{2} 6$ was isolated by the acid-guanidinium/thiocyanate/phenol/chloroform (AGPC) extraction method described by Chomczynski \& Sacchi (1987). Finally, the RNA was dissolved in TE buffer at $65^{\circ} \mathrm{C}$ and immediately electrophoresed on agarose gel. The RNA from the gel was transferred to a nitrocellulose membrane and fixed. The galK gene in a $1.4 \mathrm{~kb} \mathrm{BamHI-AccI}$ fragment was cut out from plasmid pGK6 and gel-purified. This was labelled with $\left[\alpha^{32} \mathrm{P}\right] \mathrm{dATP}$ by nick-translation and used as probe for hybridization to galK mRNA on a membrane filter at $65^{\circ} \mathrm{C}$ by the procedure of Sambrook et al. (1989). The filter was washed, dried and exposed to X-ray fast film (X-OMAT-AR, Kodak) and the autoradiogram developed.

Radioactivity measurement. Radioactivity was determined in a Beckman liquid scintillation counter model LS 5000 using a nonaqueous cocktail.

Protein determination. Protein was quantified by the Lowry method.

Reproducibility of results. All the experiments described in this paper were repeated two or three times, with reproducible results being obtained each time. Representative results of one set of experiments have been presented in Figs $1-5$. In other cases (Fig. 6, Table 2), means and standard deviations of the data from three different experiments have been presented.

\section{RESULTS}

Glutamate is essential for galactose-dependent growth and induction of galactokinase in $\boldsymbol{M}$. smegmatis

Fig. 1(a) shows the kinetics of growth and galactokinase expression in $M$. smegmatis. The data reveal that the bacterium could not grow on galactose as the carbon source unless glutamate was also present at a low concentration $(0.05 \%)$. Also, the growth of the bacteria was much faster in the presence of galactose plus glutamate than it was in the presence of glutamate alone. Stationary-phase cultures of $\mathrm{mc}^{2} 6$ growing separately on galactose and glutamate resumed steady growth when glutamate and galactose, respectively, were added. The kinase reaction is a key step in the metabolic utilization of galactose (Kalckar, 1958). Surprisingly, the results in Fig. 1(a) show that a significant amount of kinase was produced in the glutamate-grown cells but none at all in the galactose-grown cells. The level of this enzyme in the cells grown on galactose in the presence of glutamate was about 3.5-fold higher than that in the glutamate-grown cells (the enzyme levels at their peaks at $72 \mathrm{~h}$ in Fig. 1a were compared). We conclude that $\mathrm{mc}^{2} 6$ is unable to grow on galactose in the absence of glutamate because this amino acid is absolutely necessary for the induction of kinase.

Glutamate plays a key role in the biosynthesis of other amino acids (Umbarger, 1978). The primary role of glutamate may thus be to reduce the lag phase during growth of $\mathrm{mc}^{2} 6$ by providing carbon and nitrogen and generating an intracellular pool of other amino acids. However, when the bacteria were first grown to early exponential phase on glycerol without any amino acid and then the galactokinase induction was studied, even then galactose alone failed to induce the enzyme, while glutamate alone did so at low level which was enhanced further by galactose or fucose (Fig. 1b). This suggests that glutamate possibly plays a specific regulatory role in galK expression rather than in promoting bacterial growth.

To determine the effect of varying the concentration of glutamate on galK expression in $\mathrm{mc}^{2} 6$, in both the presence and absence of galactose, an experiment was done as described in Fig. 2. The results reveal that with the increase of glutamate concentration in the medium, the expression of kinase was increased in the absence of galactose (Fig. 2a) and decreased in its presence (Fig. $2 b)$. However, growth was not at all inhibited under the latter condition (data not shown). These results suggest that glutamate at high concentration $(0.2 \%)$ is quite effective for a high level of galK expression in the absence of galactose, but is inhibitory in the presence of this sugar.

When the effect of other amino acids on galactokinase induction in $M$. smegmatis was examined, it was observed that (i) tyrosine, serine, valine, isoleucine, glycine and methionine had practically no effect; (ii) two glutamate-generating amino acids, proline and histidine, 


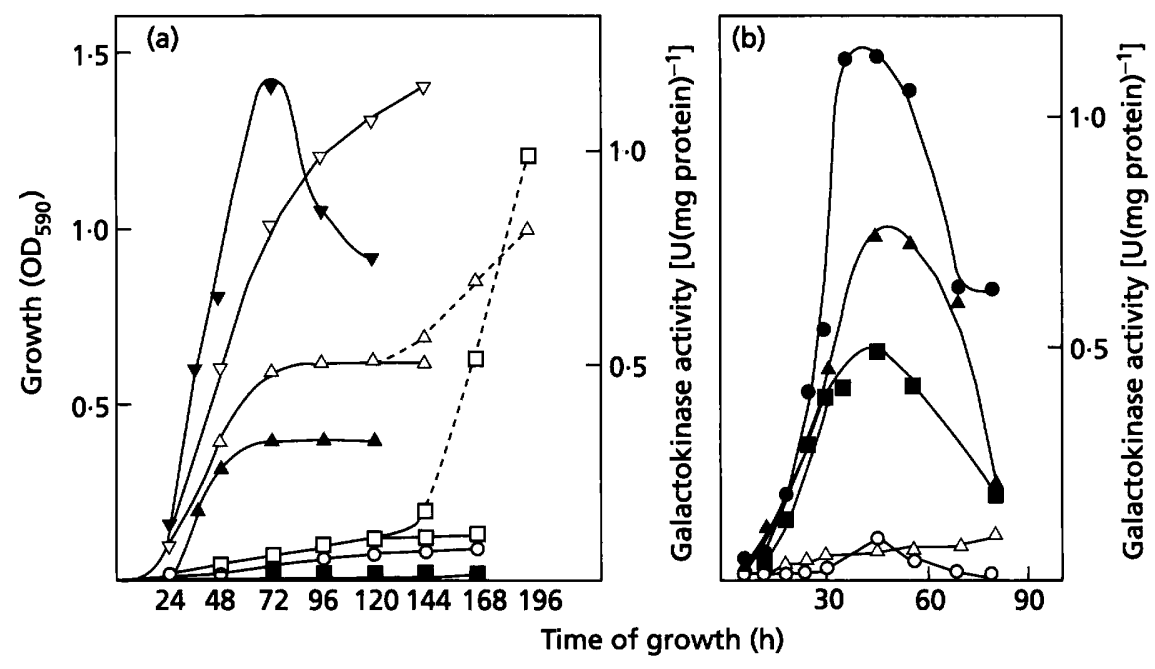

Fig. 1. (a) Effect of glutamate on galactose-dependent growth and galactokinase induction in $M$. smegmatis mc ${ }^{2} 6$. Cultures were grown in basal $7 \mathrm{H} 9$ medium for $24 \mathrm{~h}$ for glutamate starvation and then inoculated into the same medium in different flasks with or without supplement(s) (galactose, $0.2 \%$; glutamate, $0.05 \%$ ). At different times two aliquots were taken from each culture; one was used to monitor growth, while the other was used to assay galactokinase. At $120 \mathrm{~h}$, aliquots from cultures containing only glutamate $(\triangle)$ and only galactose $(\square)$ were taken; to these were added $0.2 \%$ galactose and $0.05 \%$ glutamate, respectively, and the growth was monitored for $196 \mathrm{~h}$ (indicated by a broken line). For further experimental details, see Methods. Open symbols, growth; solid symbols, kinase activity. $0, B a s a l ; \square, \square$, basal + galactose; $\Delta, \Delta$, basal + glutamate; $\nabla, \nabla$, basal + galactose + glutamate. (b) Effect of glutamate on galactokinase induction in $\mathrm{mc}^{2} 6$ growing in the presence of glycerol. Cultures were grown in basal 7H9 medium for $24 \mathrm{~h}$ for glutamate starvation, after which glycerol was added to $0.2 \%$. The culture was grown to around $O D_{590} 0.2$ (early exponential phase) and then divided into five equal portions. One portion received no supplement, the other four received galactose (0.2\%), glutamate $(0.05 \%)$ and fucose $(2 \mathrm{mM})$ in different combinations. Aliquots were taken out at different times and galactokinase activity was assayed. For further details, see Methods. $O$, Basal; $\triangle$, basal + galactose; $\boldsymbol{q}$, basal + glutamate; $A$, basal +fucose + glutamate; 0 , basal + glutamate + galactose. The basal $7 \mathrm{H} 9$ medium contained $0.2 \%$ glycerol in all five portions.

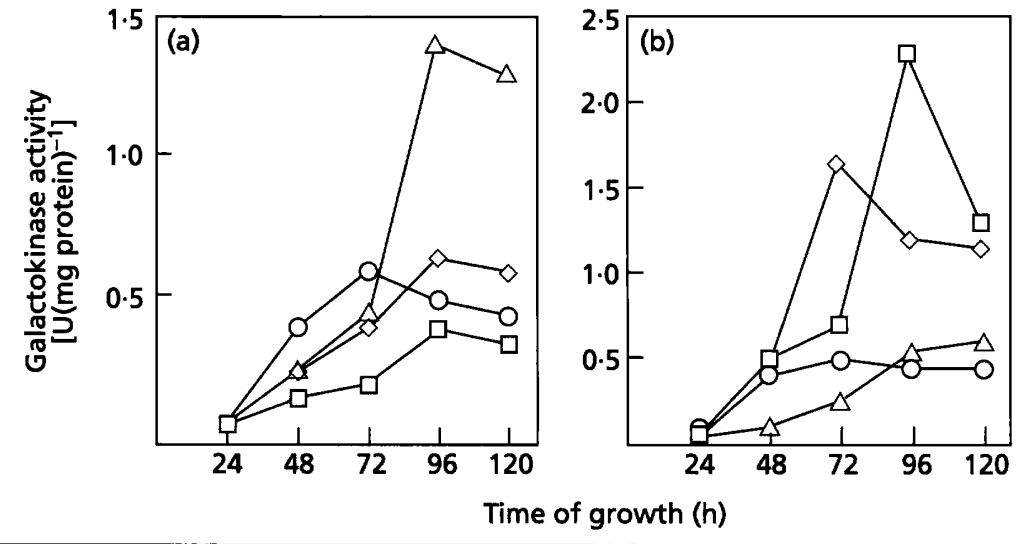

Fig. 2. Galactokinase expression in $m c^{2} 6$ as a function of glutamate concentration. The experiment was done as described in Fig. 1(a) with different concentrations of glutamate in the absence and presence of galactose. Aliquots were taken at different times and galactokinase was assayed. For other details, see Methods. (a) No galactose present, (b) $0.2 \%$ (fixed) galactose present. Glutamate concentration was as follows: $\square$, $0.02 \% ; \diamond, 0.05 \% ; 0,0.1 \% ; \triangle, 0.2 \%$.

could induce the enzyme to the same maximum level as achieved by glutamate but with relatively slower kinetics; (iii) all other amino acids were effective, with efficiencies varying from 10 to $59 \%$ of that shown by glutamate; and (iv) the glutamate-derived compounds such as 2-oxoglutarate and $\gamma$-aminobutyrate did not show any effect in this regard (data not shown). This suggests that the induction of galactokinase is specifically responsive to glutamate, and that the other amino acids which show a positive effect possibly do so by generating an intracellular pool of glutamate at varying levels.

\section{Expression of UDP-galactose 4-epimerase is constitutive in $M$. smegmatis}

In $E$. coli the three gal enzymes, epimerase, transferase and kinase, are organized in one operon and all are inducible by galactose or fucose (Adhya, 1987). Fig. 3 shows that in $M$. smegmatis the level of epimerase expressed in the presence of glutamate plus galactose was maintained almost at a constant level throughout the induction period starting from zero time, while the expression of kinase followed a typical induction profile under identical conditions. It is also seen that nearly the 


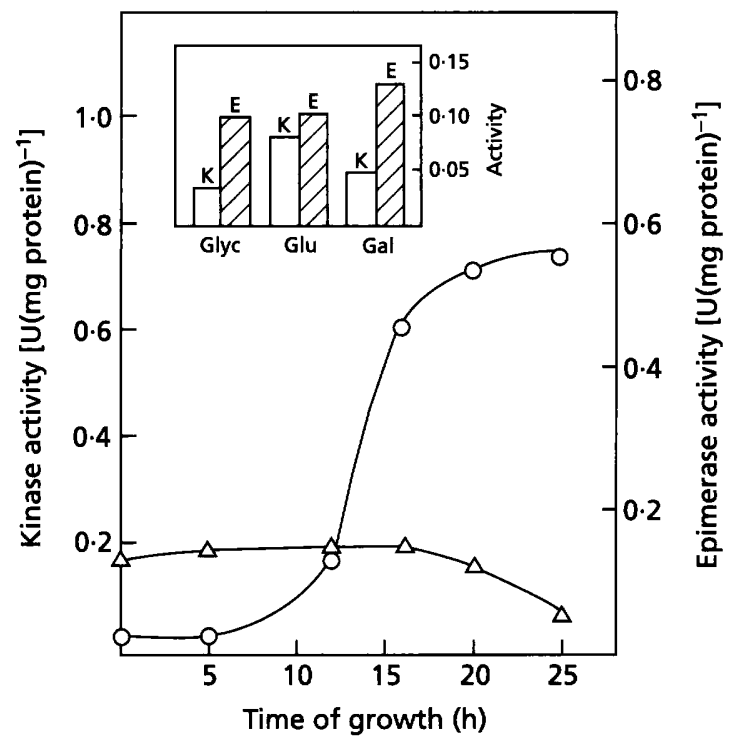

Fig. 3. UDP-galactose 4-epimerase activity in $\mathrm{mc}^{2} 6$. The experiment was done as described in Fig. 1(b) except that fucose supplementation was omitted. Kinase and epimerase were assayed from the same aliquots of the cultures. Inset bar diagrams: kinase $(K)$ and epimerase $(E)$ were determined after $25 \mathrm{~h}$ of growth following supplementations. Glyc, $0.2 \%$ glycerol; Glu, $0.05 \%$ glutamate $+0.2 \%$ glycerol; Gal, $0.2 \%$ galactose $+0.2 \%$ glycerol. The glutamate and galactose cultures also contained $0.2 \%$ glycerol. For further details see Methods. $O$, Kinase; $\triangle$, epimerase.

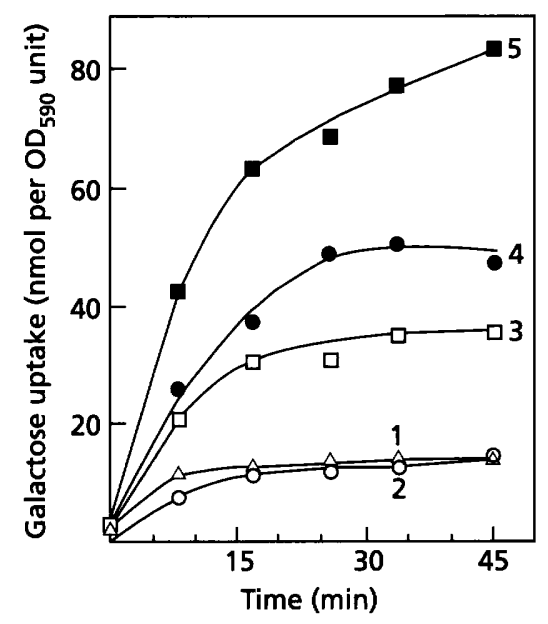

Fig. 4. Expression of galactose uptake activity in $\mathrm{mc}^{2} 6$. Bacteria were grown in basal medium for $24 \mathrm{~h}$ for glutamate starvation and then divided into five equal portions which received glycerol $(0.2 \%)$, glutamate $(0.05 \%)$, galactose $(0.2 \%)$ either singly or in different combinations. These were then grown to around $O D_{590} 1$ and galactose uptake activity was determined. For further details, see Methods. $\triangle$, Basal; $O$, basal+glycerol: $\square$, basal+glutamate; 0 , basal+galactose; $\mathbf{\square}$, basal+ galactose + glutamate.

same amounts of epimerase were present in the cells grown separately on glycerol, galactose or glutamate (see inset bar diagrams in Fig. 3). We conclude that the

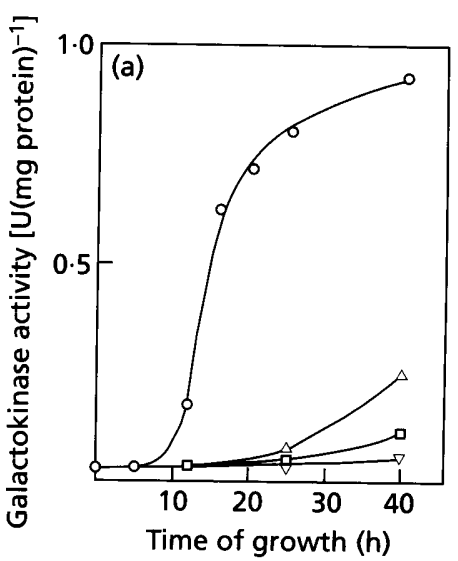

(b)

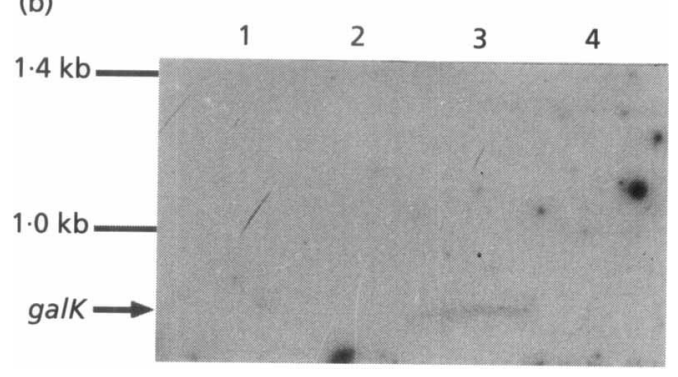

Fig. 5. (a) Effect of rifampicin on galactokinase induction in $\mathrm{mc}^{2} 6$. Cultures were grown in basal $7 \mathrm{H} 9$ broth for $24 \mathrm{~h}$, and then glycerol was added to $0.2 \%$ and grown further to around $\mathrm{OD}_{590} 0.2$. The culture was then divided into two equal portions. Glutamate $(0.05 \%)$ and galactose $(0.2 \%)$ were added to one, while only glutamate $(0.05 \%)$ was added to the other. Each of the two portions was again subdivided into two; rifampicin at $25 \mu \mathrm{g} \mathrm{ml}^{-1}$ was added to one from each portion, with the other remaining as a control. Cultures were grown and aliquots were taken at different times for galactokinase assay. For further details, see Methods. $\triangle$, Glutamate; $O$, glutamate + galactose; $\nabla$, glutamate + Rif; $\square$, glutamate + galactose + Rif. After glutamate starvation, $0.2 \%$ glycerol was added to all portions. (b) Northern blot analysis of RNA isolated from $M$. smegmatis grown under different conditions. Experimental methods were as for (a) except that rifampicin was omitted; the four portions of cultures contained basal medium only (lane 1), $0.2 \%$ galactose (lane 2), $0.2 \%$ galactose $+0.05 \%$ glutamate (lane 3), and $0.05 \%$ glutamate (lane 4). All the cultures contained $0.2 \%$ glycerol. Total RNA was isolated and Northern blot analysis was done as described in Methods. The positions of dsDNA markers in kb and galK mRNA are indicated.

expression of epimerase is constitutive and is not at all influenced by glutamate and/or galactose.

\section{Galactose and glutamate independently induce galactose transport activity in $\boldsymbol{M}$. smegmatis}

To clarify if glutamate regulates the expression of galK in $M$. smegmatis by controlling the expression of galactose uptake activity, an experiment was done as described in Fig. 4. The data indicate that each of the glutamate-grown and galactose-grown $\mathrm{mc}^{2} 6$ cells had higher levels of galactose uptake activity than the glycerol-grown cells. In the cells grown on galactose plus glutamate, the above uptake activity appears to be 

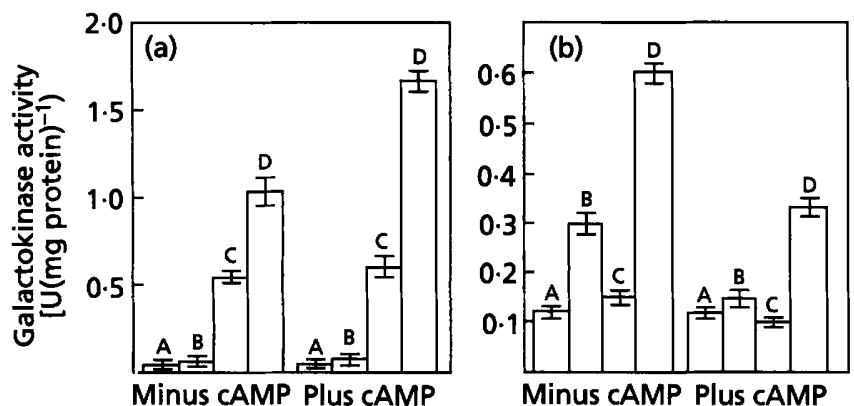

Fig. 6. Effect of CAMP on galactokinase expression in (a) wild-type $m c^{2} 6$ and (b) the gin-1 mutant. Cultures were grown in presence of glycerol to $O_{590} 0.2$, as described in Fig. 5. Galactose $(0.2 \%)$, glutamate $(0.05 \%)$ and CAMP $(10 \mathrm{mM})$ were added to different aliquots in the combinations shown and the cultures were grown further. After $30 \mathrm{~h}$, kinase activity was assayed. For further details, see Methods. A, basal 7H9 broth; B, basal + galactose; C, basal + glutamate; $D$, basal + galactose + glutamate. In all the sets, after the glutamate starvation step, the basal medium contained $0.2 \%$ glycerol. the sum of those in the cells grown separately on these two metabolites. However, glutamate did not compete with galactose for its transport into the cells grown on galactose plus glutamate (results not shown). This suggests that $M$. smegmatis does not use the glutamate uptake pathway for galactose transport. The additive effect seen in the presence of both glutamate and galactose is possibly due to the induction of the uptake activity separately by these two compounds. It is interesting to note that although the galactose-grown cells showed galactose uptake activity nearly 1.5 -fold higher than the glutamate-grown cells (Fig. 4), galactokinase was induced in the latter cells but not in the former (Fig. 1). It is not clear whether the galactoseinduced uptake activity was due to L-arabinose permease that is induced by galactose (Izumori et al., 1976, 1978). However, what is clear is that the induction of galactose uptake activity by glutamate is not a deciding factor in the induction of kinase.

\section{Glutamate regulates the expression of galK in $M$. smegmatis at the transcriptional level}

The question now arises as to whether the expression of galactokinase is regulated by glutamate at the transcriptional level. It is known that rifampicin is a potent inhibitor of transcription in bacteria (McClure \& Cech, 1978). The results in Fig. 5(a) show that the induction of kinase by glutamate in both the presence and absence of galactose was significantly inhibited by rifampicin. The results of the Northern hybridization experiment in Fig. $5(b)$ show that the galK-specific mRNA was detectable in the bacteria after $20 \mathrm{~h}$ growth in the presence of both galactose and glutamate (lane 3) but not in those grown on galactose (lane 2) or even glutamate (lane 4) alone under identical conditions. We conclude that the presence of both galactose and glutamate is essential for efficient transcription of the galK gene in M. smegmatis.

\section{Exogenous CAMP stimulates galK expression in $M$. smegmatis only in the presence of both glutamate and galactose}

Transcription of the gal operon in E. coli is activated by cAMP and CRP (Adhya, 1987). The results in Fig. 6(a) demonstrate that in wild-type $\mathrm{mc}^{2} 6$, the expression of
galK in the presence of glutamate plus galactose was stimulated $1 \cdot 7$-fold by exogenously added cAMP over that in its absence. However, cAMP could neither stimulate the glutamate-regulated expression of the enzyme nor activate the process in the presence of galactose alone. This suggests that cAMP positively regulates the expression of kinase in $M$. smegmatis in the presence of both glutamate and galactose but does not act in the process regulated by glutamate alone. cAMP needs a receptor protein, CRP, for the activation of gene transcription in bacteria (Kolb et al., 1993). It is known that wild-type $M$. smegmatis produces intracellular cAMP (Padh \& Venkatisubramanian, 1978) as well as CRP (Lee, 1979). A 1·7-fold stimulation of kinase expression in wild-type $\mathrm{mc}^{2} 6$ by exogenous cAMP over that in the absence of the above nucleotide therefore suggests that possibly the wild-type cells growing under the conditions of the experiment do not maintain the optimum level of cAMP that is needed for maximum stimulation of galK expression.

\section{Expression of galK in a glutamate-independent galactose-utilizing mutant of $\boldsymbol{M}$. smegmatis occurs in the absence of glutamate and is stimulated further in the presence of glutamate plus galactose}

To understand the role of glutamate in galK expression, mutants of $\mathrm{mc}^{2} 6$ capable of growing on galactose in the absence of any amino acid were isolated by the procedure described in Methods. These were called $\mathrm{mc}^{2} 6$ gin (glutamate independent) mutants. These mutants could grow slowly on galactose as the only carbon source (results not shown). The expression of galK in one of these mutants, gin-1, was studied under different conditions. The data in Fig. $6(\mathrm{~b})$ reveal that in basal 7H9 broth, the gin-1 mutant could express kinase at a significant level, which was increased twofold in the presence of galactose alone and fourfold in the presence of both glutamate and galactose, while the amino acid alone had no effect. The data in Fig. 6(b) also show that in this mutant, cAMP had no effect on the expression of kinase either in basal 7H9 broth or in the same medium containing glutamate alone, while it reduced expression to the basal level in the presence of galactose alone and to around $45 \%$ of that expressed under glutamate plus galactose. 
(a)
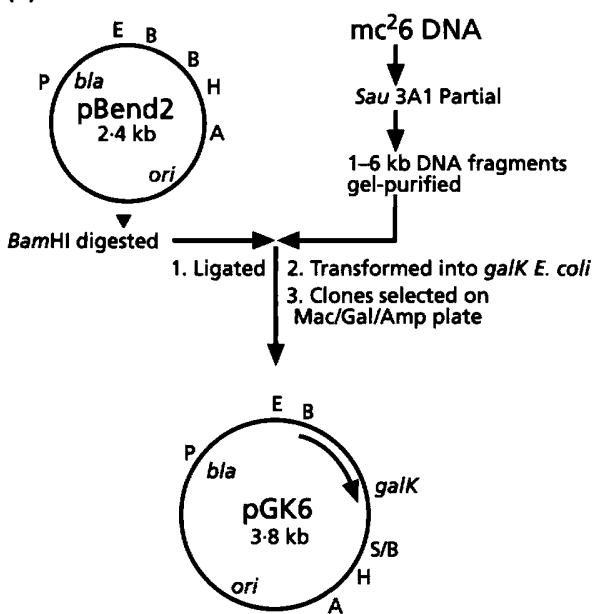

(b)
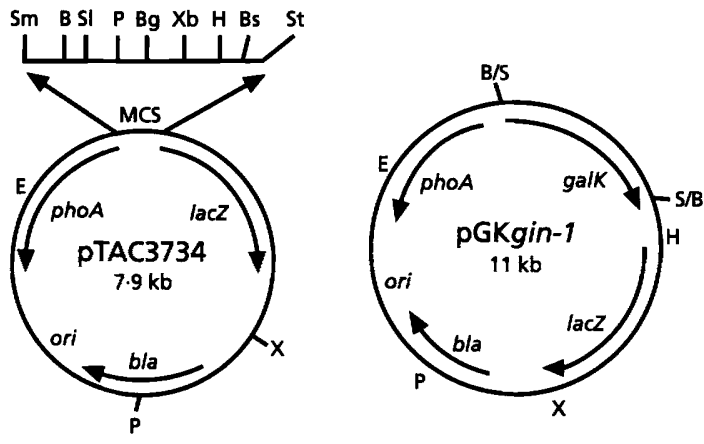

Fig. 7. (a) Schematic representation of the molecular cloning of mycobacterial galK gene in $E$. coli. Preparation of the Sau3AI genomic library of wild-type $M$. smegmatis $\mathrm{mc}^{2} 6$ in plasmid pBend2 is described in Methods. The genomic library of the $\mathrm{mc}^{2} 6$ gin-1 mutant was prepared following the same strategy except that plasmid pBend 2 and wild-type $\mathrm{mc}^{2} 6$ DNA were replaced by plasmid pTAC3734 and mc $^{2} 6$ gin-1 mutant DNA, respectively. The plasmids from these two libraries were transformed into galK $E$. coli and plated on Mad/Gal/Amp agar. After $16-20 \mathrm{~h}$ at $37^{\circ} \mathrm{C}$, the red colonies were selected and purified. The plasmids were isolated and retransformed in galK E. coli when $100 \%$ of the transformants on Mac/Gal/Amp agar were red. These plasmids were taken as true gal $K$ clones. The plasmids carrying the galK gene from wild-type $\mathrm{mc}^{2} 6$ were called pGK plasmids and that from $\mathrm{mc}^{2} 6$ gin-1 mutant was called pGKgin-1. (b) Maps of pTAC3734 and pGKgin-1. Restriction sites: A, Accl; B, BamHI; Bg, BgllI; Bs, BstBI; E, EcoRI; H, HindllI; P. Pstl; S, Sau3Al; Sl, Sall; Sm, Smal; St, Stul; X, Xhol; Xb, Xbal. MCS, multiple cloning sites.

\section{Expression of mycobacterial galK in $E$. coli is dependent on CAMP and CRP}

By screening a Sau3AI library of $M$. smegmatis genomic DNA in pBend2 (see Methods and Fig. 7) four plasmid clones containing DNA inserts of sizes ranging from 1.4 to $4 \mathrm{~kb}$ carrying the galK gene were obtained. These plasmids, called pGK1, pGK3, pGK4 and pGK6, could all complement an E. coli galK mutant but not galE and galT mutants for galactose utilization (results not shown). The galactokinase level produced in a galK strain of E. coli by one of these plasmids, pGK6, carrying the smallest insert, is shown in Table 2 . As pBend 2 does not carry any promoter within or around the multiple cloning sites (Zweib et al., 1989), the above results suggest that these pGK plasmids carry the galK gene with its upstream promoter which is expressed in E. coli and that the galE and galT genes are either absent or that if any of them is present, especially in the $4 \mathrm{~kb}$ insert, that it is not expressed. This implies that possibly the latter two gal genes are not members of the galK operon in $M$. smegmatis. It may be noted that although the mycobacterial promoters studied so far are not expressed in E. coli (Bashyam et al., 1996; Clark-Curtiss $e t$ al., 1985; Das Gupta et al., 1993; Kiesser et al., 1986), the above galK promoter is expressed. While this may appear very unusual, it is not surprising because it is known that the $16 \mathrm{~S}$ rRNA promoter of $M$. leprae is expressed in E. coli (Sela \& Clark-Curtiss, 1991).

It was observed further that in the crp and cya deletion mutants of E. coli, galactokinase was expressed from the pGK plasmids at drastically reduced levels. The galactokinase data with pGK6 are shown in Table 2. In the $E$ coli cya deletion mutant, the expression of kinase from this plasmid was increased about 36 -fold in the presence of exogenously added cAMP over that in its absence. We conclude that an efficient expression of mycobacterial galK from its own promoter requires cAMP, and that $E$. coli CRP can substitute the mycobacterial protein for the activation of mycobacterial galK promoter by cAMP. The galK gene with its upstream regulatory region from the gin-1 mutant was cloned in E. coli to give plasmid pGKgin-1 (see Methods and Fig. 7). A comparison of the data on the expression of galactokinase (Table 2) from pGK6 and pGKgin-1 in galK E. coli, and cya and crp deletion mutants under identical conditions, suggests that the expression of galK from these two plasmids responds to the $E$. coli regulatory signals exactly in an identical manner. This implies that the gin-1 mutation has not affected any of the upstream positive regulatory sites of galK.

\section{DISCUSSION}

In this paper we show that the expression of galactokinase in $M$. smegmatis is regulated by L-glutamate and cAMP. Glutamate also induces galactose uptake activity. From the data on the expression of galK in wildtype $\mathrm{mc}^{2} 6$ and its gin mutant in the absence and presence of galactose, glutamate and cAMP, either alone or in different combinations, we suggest a model of galK regulation that has the following features. (i) The expression of $\mathrm{galK}$ occurs in two distinct ways from two different promoters which are differently regulated; (ii) galactose alone is totally ineffective in inducing the enzyme from both the promoters; (iii) galK expression from one promoter, say galP1, is dependent on glutamate only, while that from the second, say galP2, requires both galactose and glutamate; (iv) cAMP activates the latter promoter but not the former.

In E. coli, the gal genes galE, galT and galK are clustered 
Table 2. Expression of galactokinase from pGK6 and pGKgin-1 plasmids in cya and crp deletion mutants of $E$. coli

Bacteria were grown in M9 medium supplemented with Casamino acids and containing $2 \mathrm{mM}$ fucose. Wherever needed, cAMP was used at $5 \mathrm{mM}$. Galactokinase data from cells containing plasmids were corrected for the values obtained with corresponding control cultures (no plasmid). In all the cases, means of the data from three independent experiments are presented, $\pm \mathrm{SD}$. For other details, see Methods and text.

\begin{tabular}{|c|c|c|c|}
\hline \multirow[t]{2}{*}{ E. coli genotype } & \multicolumn{3}{|c|}{$\begin{array}{l}\text { Galactokinase activity (U per } \mathrm{OD}_{590} \text { unit) in cells containing } \\
\text { plasmid: }\end{array}$} \\
\hline & None (control) & pGK6 & pGKgin-1 \\
\hline galK $^{*}$ & $1 \cdot 20 \pm 0 \cdot 16$ & $93.97 \pm 12.47$ & $93 \cdot 27 \pm 25 \cdot 70$ \\
\hline $\operatorname{galK}^{+*}$ & $17 \cdot 11 \pm 0 \cdot 62$ & $91 \cdot 49 \pm 6 \cdot 27$ & $93 \cdot 70 \pm 4 \cdot 74$ \\
\hline $\operatorname{del}($ cya $) g_{\text {galK }}^{+}$ & $3.92 \pm 0.32$ & $2 \cdot 70 \pm 0 \cdot 26$ & $1.79 \pm 0.52$ \\
\hline dell(cya)galK $K^{+}$cAMP & $17 \cdot 24 \pm 0 \cdot 84$ & $97 \cdot 24 \pm 1.99$ & $93 \cdot 30 \pm 8 \cdot 32$ \\
\hline $\operatorname{del}(c r p) g a l K^{+}$ & $0.71 \pm 0.32$ & $10 \cdot 24 \pm 1 \cdot 06$ & $4 \cdot 28 \pm 0.67$ \\
\hline
\end{tabular}

* Both these strains ( $g a l K$ and $\left.g a l K^{+}\right)$of E. coli were $c y a^{+} c r p^{+}$.

in one operon under the control of two different promoters, P1 and P2, located 5 bp apart (Adhya, 1987). These promoters are repressed independently by two different repressors, GalR (Majumdar et al., 1987) and GalS (Weickert \& Adhya, 1992), and are both derepressed by galactose. The cAMP-CRP complex activates $P 1$ and inhibits $P 2$ (Adhya, 1987). We have shown that in M. smegmatis, while the expression of galK is inducible and is regulated by glutamate and cAMP (see Results), that of galE is constitutive and is not influenced by any of the components which regulate galK expression. These suggest that in this bacterium, the expression of galK and galE is possibly controlled by different promoters. Agrobacterium tumefaciens expresses epimerase constitutively, while it does not code for kinase (Uttar et al., 1993). In Streptomyces lividans, the gal genes are expressed from two different promoters; while galE and galK are transcribed constitutively from galP2, galT is transcribed from galP1 only under inducing conditions (Fornwald et al., 1987; Mattern et al., 1993). It appears, therefore, that the organization and control of expression of gal genes are different in different micro-organisms.

What is the role of glutamate in galK expression and what is the identity of the actual inducer of the galK operon in M. smegmatis? The regulation of a gene by its promoter may be negative as well as positive. According to the general model of a negatively regulated operon (Jacob \& Monod, 1961), the mycobacterial galK operon should be negatively controlled by its specific gal repressor. Studies with the E. coli gal operon in vivo (Adhya, 1987) and its gal repressor in vitro (Majumdar \& Adhya, 1984) indicate that galactose is the inducer of the gal operon in $E$. coli. If it is assumed that in $M$. smegmatis galactose is also an inducer which binds the gal repressor specifically and inactivates it, and that glutamate does not bind the repressor, then how does glutamate help activate galP1 in the absence of ga- lactose? It may be that galP1 is not repressed by the repressor, while galP2 is. Under these conditions the transcription from galP1 may be initiated only in the presence of glutamate acting as a positive regulator. For the expression of galK from galP2, derepression by galactose is essential but is not sufficient for activation by cAMP unless glutamate is also present.

The data on galactokinase expression in the gin-1 mutant (Fig. 6b) may be explained in the light of the above assumptions as follows. The gin-1 mutant expresses galK in the absence of glutamate and galactose. In the presence of galactose, this expression of kinase was increased twofold in the absence of glutamate and fourfold in its presence, while the amino acid alone had no effect. cAMP reduced the expression in the presence of galactose plus glutamate nearly to the basal level. This implies that in the gin-1 mutant, expression from galP1 can occur without derepression by galactose, while that from galP2 requires both derepression by galactose and activation by glutamate. In the absence of any apparent defect in the positive regulatory sites in the gin-1 mutant, as suggested by the galactokinase data with pGKgin-1 plasmid in E. coli (Table 2), the other possibility is that the mutation has affected a transacting regulatory component, which is likely to be a glutamate-binding protein, and that the mutant version of this protein does not require glutamate for the transcription from galP1. Therefore a twofold increase of galK expression in this mutant after derepression by galactose in the absence of glutamate (Fig. 6b) over the basal level may be viewed as being due to an activation of galP2 by endogenous cAMP which does not require the amino acid in the presence of glutamate-independent binding protein (in wild-type cells, cAMP cannot activate galP2 without glutamate). A further twofold increase of kinase activity by glutamate in the galactosederepressed cells (a total of a fourfold increase over the basal level) is possibly achieved through activation by 
both glutamate and intracellular cAMP (Fig. 6b). This suggests that the mutant glutamate-binding protein can respond to glutamate in further activating galP2 in the presence of cAMP but not in its absence. However, in the presence of excess cAMP (exogenously supplied), the expression from galP2 is possibly totally inhibited without affecting glutamate-independent, galP1-dependent basal expression in this mutant.

In E. coli, a leucine-responsive global regulatory protein, Lrp, regulates the expression of certain operons positively and others negatively, both at the transcriptional level, and binding of leucine with Lrp affects such regulation (Ernsting et al., 1992; Willins et al., 1991). It is not clear from the present data whether glutamate and cAMP bind to the same protein or two different proteins for activation of galP2, and whether the same glutamatebinding protein regulates both galP1 and galP2. The fact that the expression of mycobacterial galactokinase from both pGK6 and pGKgin-1 in E. coli does not require glutamate (M. Basu \& N.C. Mandal, unpublished results) suggests that it is possibly the difference between the cAMP-binding protein molecules of $M$. smegmatis and $E$. coli that makes the former bacterium glutamatedependent for galK expression. Further studies will identify and characterize the two presumptive promoters, galP1 and galP2, and clarify the mechanism(s) of their regulation by glutamate and cAMP in M. smegmatis at the molecular level.

\section{ACKNOWLEDGEMENTS}

We thank Drs S. Adhya, H. Aiba, B. Bloom and D. Chattoraj for bacterial strains. This work was supported by ad hoc Research Fellowships to S.R. and M.B. from the Council of Scientific and Industrial Research (CSIR), Government of India, New Delhi. We also thank Drs Asis Das and N. Das for critically reading the manuscript and providing some valuable suggestions.

\section{REFERENCES}

Adhya, S. (1987). The galactose operon. In Escherichia coli and Salmonella typhimurium: Cellular and Molecular Biology, pp. 1503-1512. Edited by F. C. Neidhardt and others. Washington, DC: American Society for Microbiology.

Adhya, S. L. \& Miller, W. (1979). Modulation of the two promoters of the galactose operon of Escherichia coli. Nature 279, 492-494.

Anderson, A. B. \& Hansen, E. B. (1993). Cloning of the lys $A$ gene from Mycobacterium tuberculosis. Gene 124, 105-109.

Bashyam, M. D., Kaushal, D., Das Gupta, S. K. \& Tyagi, A. K. (1996). A study of the mycobacterial transcription apparatus: identification of novel features in promoter elements. J Bacteriol 178, 4847-4853.

Chaudhuri, B., Sau, S, Datta, H. J. \& Mandal, N. C. (1993). Isolation, characterization, and mapping of temperature-sensitive mutations in the genes essential for lysogenic and lytic growth of the mycobacteriophage L1. Virology 194, 166-172.

Chomczynski, P. \& Sacchi, N. (1987). Single-step method of RNA isolation by acid guanidine thiocyanate-phenol-chloroform extraction. Anal Biochem 162, 156-159.

Clark-Curtiss, J. E., Jacobs, W. R., Jr, Docherty, M. A., Ritchie, L. R. \& Curtiss, R., Jr (1985). Molecular analysis of DNA and the construction of genomic libraries of Mycobacterium leprae. J Bacteriol 161, 1093-1102.

Dale, J. W. \& Patki, A. (1990). Mycobacterial gene expression and regulation. In Molecular Biology of Mycobacteria, pp. 173-198. Edited by J. J. McFadden. London: Surrey University Press.

Das Gupta, S. K., Bashyam, M. D. \& Tyagi, A. K. (1993). Cloning and assessment of mycobacterial promoters by using a plasmid shuttle vector. J Bacteriol 175, 5186-5192.

Ernsting, B. R., Atkinson, M. R., Ninfa, A. J. \& Matthews, R. G. (1992). Characterization of the regulon controlled by the leucineresponsive regulatory protein in Escherichia coli. J Bacteriol 174, 1109-1118.

Fornwald, J. A., Schmidt, C. W., Adams, C. W., Rosenberg, M. \& Brawner, M. E. (1987). Two promoters, one inducible and one constitutive, control transcription of the Streptomyces galactose operon. Proc Natl Acad Sci USA 84, 2130-2134.

Garbe, T., Jones, C., Charles, L., Dougan, G. \& Young, D. (1990). Cloning and characterization of the aroA gene from Mycobacterium tuberculosis. J Bacteriol 172, 6774-6782.

Grange, J. M. (1983). The genetics of mycobacteria and mycobacteriophages. In The Biology of the Mycobacteria, pp. 309-350. Edited by C. Ratledge \& J. Stanford. New York: Academic Press. Greenberg, J. \& Woodley, C. L. (1985). Genetics of mycobacteria. In: The Mycobacteria : a Source Book, pp. 629-639. Edited by G. P. Kubica \& L. G. Wayne. New York: Marcel Dekker.

Hinshelwood, S. \& Stoker, N. G. (1992). Cloning of mycobacteria] histidine synthesis-genes by complementation in Mycobacterium smegmatis auxotroph. Mol Microbiol 6, 2887-2896.

Izumori, K., Yamanaka, K. \& Elbein, A. D. (1976). Pentose metabolism in Mycobacterium smegmatis: specificity of induction of pentose isomerases. J Bacteriol 128, 587-591.

Izumori, K., Ueda, Y. \& Yamanaka, K. (1978). Pentose metabolism in Mycobacterium smegmatis: comparison of $\mathrm{L}$-arabinose isomerases induced by L-arabinose and D-galactose. J Bacteriol 133 , 413-414.

Jacob, F. \& Monod, J. (1961). Genetic regulatory mechanisms in the synthesis of proteins. J Mol Biol 3, 318-356.

Jacobs, W. R., Jr (1992). Advances in mycobacterial genetics: new promises for old diseases. Immunobiology 184, 147-156.

Jacobs, W. R., Jr, Docherty, M. A., Curtiss, R. \& Clark-Curtiss, J. E. (1986). Expression of Mycobacterium leprae genes from a Streptococcus mutant promoter in Escherichia coli K-12. Proc Natl Acad Sci USA 83, 1926-1930.

Kalckar, H. M. (1958). Uridinediphosphogalactose: metabolism, enzymology, and biology. Adv Enzymol Relat Areas Mol Biol 20, $111-134$

Kasuka, T., Kohsaka, K., Fukunishi, Y. \& Akimori, H. (1981). Isolation and identification of mycolic acids in Mycobacterium leprae and Mycobacterium lepraemurium. Int J Lepr 49, 406-466.

Kieser, T., Moss, M. T., Dale, J. W. \& Hopwood, D. A. (1986). Cloning and expression of Mycobacterium bovis BCG DNA in Streptomyces lividans. J Bacteriol 168, 72-80.

Kolb, A., Busby, S., Garges, S. \& Adhya, S. (1993). Transcriptional regulation by cAMP and its receptor protein. Annu Rev Biochem 62, 749-795.

Lee, C. H. (1979). Metabolism of cyclic AMP in non-pathogenic Mycobacterium smegmatis. Arch Microbiol 120, 35-39.

Lyon, R. H., Rogers, P., Hall, W. H. \& Lichstein, H. C. (1967). Inducible glutamate transport in mycobacteria and its relation to glutamate oxidation. J Bacteriol 94, 92-100.

McClure, W. R. \& Cech, C. L. (1978). On the mechanism of 
rifampicin inhibition of RNA synthesis. $J$ Biol Chem 253, 8949-8956.

Majumdar, A. \& Adhya, S. (1984). Demonstration of two operator elements in gal: in vitro repressor binding studies. Proc Natl Acad Sci USA 81, 6100-6104.

Majumdar, A., Rudikoff, S. \& Adhya, S. (1987). Purification and properties of $g a l$ repressor: $\mathrm{pL}-$ galR fusion in $\mathrm{pKC} 31$ plasmid vector. J Biol Chem 262, 2326-2331.

Mattern, S. G., Brawner, M. E. \& Westpheling, J. (1993). Identification of a complex operator for galP1, the glucose-sensitive, galactose-dependent promoter of the Streptomyces galactose operon. J Bacteriol 175, 1213-1220.

Miller, J. H. (1972). Experiments in Molecular Genetics. Cold Spring Harbor, NY: Cold Spring Harbor Laboratory.

Minnikin, D. E., Dobson, G., Goodfellow, M., Draper, P. \& Magnusson, M. (1985). Quantitative comparison of the mycolic acid and fatty acid compositions of Mycobacterium leprae and Mycobacterium gordonae. J Gen Microbiol 131, 2013-2021.

Padh, H. \& Venkatisubramanian, T. A. (1978). Adenylate cyclase activity of Mycobacterium smegmatis CDC46. Indian J Biochem Biophys 15, 141-143.

Prasad, R., Kalra, V. K. \& Brodie, A. F. (1976). Different mechanisms of energy coupling for transport of various amino acids in cells of Mycobacterium phlei. J Biol Chem 251, 2493-2498.

Sambrook, J., Fritsch, E. F. \& Maniatis, T. (1989). Molecular Cloning: a Laboratory Manual, 2nd edn. Cold Spring Harbor, NY: Cold Spring Harbor Laboratory.

Segal, W. \& Edwards, B. S. (1985). Carbohydrate and amino acid metabolism and control. In The Mycobacteria: A Source Book, pp. 575-594. Edited by G. P. Kubica \& L. G. Wayne. New York: Marcel Dekker.

Sela, S. \& Clark-Curtiss, J. E. (1991). Cloning and characterization of the Mycobacterium leprae ribosomal RNA promoter in Escherichia coli. Gene 98, 123-127.

Stelandre, M., Bosseloir, Y., Bruyn, J. D., Maes, P. \& Content, J. (1992). Cloning and sequence analysis of the gene encoding an NADP-dependent alcohol dehydrogenase in Mycobacterium bovis. Gene 121, 79-86.

Umbarger, H. E. (1978). Amino acid biosynthesis and its control Annu Rev Biochem 47, 533-606.

Uttar, A. D., lelpi, L. \& Ugalde, R. A. (1993). Galactose metabolism in Rhizobiaceae : characterization of Agrobacterium tumifaciens exoB mutants. J Gen Microbiol 139, 1055-1062.

Weickert, M. J. \& Adhya, S. (1992). Isorepressor of the gal regulon of Escherichia coli. J Mol Biol 226, 69-83.

Willins, D. A., Ryan, C. W., Platko, J. U. \& Calvo, J. M. (1991). Characterization of Lrp, an Escherichia coli regulatory protein that mediates a global response to leucine. J Biol Chem 266, 10768-10774.

Wilson, D. B. \& Hogness, D. S. (1969). The enzymes of the galactose operon in Escherichia coli. J Biol Chem 244, 2143-2149.

Zweib, C., Kim, J. \& Adhya, S. (1989). DNA bending by negative regulatory proteins: Gal and Lac repressors. Genes Dev 3, 606-611.

Received 15 December 1997; revised 14 March 1998; accepted 25 March 1998. 